\title{
LA $<<$ ELECCIÓN ORIGINAL $>>$ DE LOS TIEMPOS MODERNOS \\ SEGÚN MICHEL FOUCAULT
}

\author{
INSANITY AND SEXUALITY IN MODERN TIMES \\ BY MICHEL FOUCAULT
}

Fidencio Aguilar Víquez

Licenciado, maestro y doctor en filosofía. Autor de diversos libros sobre Humanidades. Miembro del Sistema Nacional de Investigadores de 2006 a 2008. Actualmente Consejero Electoral del Estado de Puebla. fidens@yahoo.com

Recibido 11-01-2013 * Aceptado 21-03-2013 * Corregido 16-04-2013

\section{Resumen}

Según Michel Foucault, la locura y la sexualidad han sido los ejes de una $<<$ elección original $>>$ de nuestro tiempo. Se entiende dicha elección como la forma de ver, de sentir, de percibir y comprender los diversos ámbitos de la actividad humana, es decir, la cultura, la política, la ciencia, las artes, la literatura. Configuran, en suma, la cosmovisión de nuestra civilización. Este trabajo muestra cómo se ha dado esto. (noviembre 2012).

Palabras clave: locura, sexualidad, cultura, civilización.

\begin{abstract}
According to Michel Foucault, madness and sexuality have been a $<<$ original Choice $>>$ of our time. It is understood that election as the way to see, feel, perceive and understand the various fields of human activity, i.e., culture, politics, science, arts, literature. In sum, configured the worldview of our civilization. This paper shows how this has been. (november 2012).
\end{abstract}

Key words: madness, sexuality, culture, civilization

\section{Introducción}


Para ubicar nuestros temas, la locura y la sexualidad, como algo actual y de uso vigente, bastaría con señalar las pretensiones, presiones y tensiones que suscitan. Cuando algo deja de tener vigencia, su uso o abuso simplemente no se dan. Y con el discurso del loco, la locura, ha generado tanto escozor, tanto temor, tanta incomodidad, que se le excluyó completamente de la incidencia social enviándolo al encierro. Tal discurso generó y genera presión, tensión, malestar. En tal sentido es un tema actual, cuando menos como un discurso periférico, no central. Y hoy, a diferencia de otros momentos históricos, los discursos periféricos han adquirido relevancia (desde luego, relevancia no central, no centralista, no como discurso de poder) como instrumentos de uso para la regionalización, para aglutinar a las diversas comunidades en sus ámbitos diversos y distantes.

El tema de la sexualidad tiene semejante envergadura y acaso más por ser una clara expresión de lo que en su momento se denominaron las revoluciones antropológicas (Copérnico, Darwin, Freud) que han marcado la historia moderna en torno al ser humano y su condición.

Gracias, en gran parte, a Darwin, el pensamiento occidental acerca de la naturaleza humana pasó por un profundo cambio. En adelante, de lo que más se hablaría había de ser de la naturaleza irracional del hombre, de sus instintos, su agresividad, su parentesco con el mundo animal. El hombre darwiniano presagió al hombre irracional de Sigmund Freud y del siglo XX. (Baumer, 1985: 333).

El propio Darwin creía en pocos principios generadores de vida y, mejor aún, en uno solo que igualaba a los seres orgánicos en el aspecto sexual:

En todos los seres orgánicos, exceptuando quizá algunos de los más bajos, la producción sexual parece ser esencialmente semejante. En todos, hasta donde se sabe hasta ahora, la vesícula germinativa es igual: de modo que todos los organismos provienen de un origen común. (Darwin, 1981: 498).

Por eso, y con razón, se suele decir que si Copérnico tiró al ser humano de su silla regia, Darwin lo igualó con los animales. Y, para rematar, Freud lo colocó en una situación de mayor irracionalidad: peor que los animales al albergar en sí los instintos más atroces: eros y tánatos. 
Todo el escenario, en particular a partir del primer tercio del siglo XX, de angustia, alienación y absurdo, hablaban no de la razón del ser humano, o que éste se condujera bajo principios racionales, como buscaban justificar los pensamientos optimistas que veían en la ciencia y en la democracia los logros más acabados de la humanidad, sino precisamente lo contrario: que los seres humanos se conducen bajo influjos y reflujos inconscientes. Y Freud pudo apreciarlo en sus investigaciones psicoanalíticas.

En efecto, si se observa la vida psíquica de un neurótico, o se miran sueños, la mayor complejidad de su mente no se explica por la conducción de su razón, sino por la represión y la negativa del sujeto para reconocer sus impulsos $\mathrm{y}$, por tanto, el conocimiento de la realidad.

Sólo mediante la introducción de estas fuerzas sexuales pueden salvarse las lagunas todavía registrables en la teoría de la represión. Quiero dejar en suspenso el averiguar si tenemos derecho a invocar lo sexual y lo infantil también para la teoría del sueño; dejo aquí incompleta esta teoría porque ya con el supuesto de que el deseo onírico proviene en todos los casos del inconsciente me he internado un paso más allá de lo comprobable. (Freud, 2008: 595)

La condición humana, desde luego, ha suscitado la reflexión desde todos los aspectos y las disciplinas en torno del tema de la sexualidad y su sentido. Una de ellas, con incidencia tanto en la filosofía como, aun, en la teología, es la de Paul Ricoeur, para quien, por ejemplo, el erotismo no puede reducirse ni identificarse al ámbito meramente instintivo natural. Para el ser humano, la sexualidad no es similar a la de los animales, simplemente porque su sexualidad es un problema para sí mismo: no hay coincidencia entre el hombre y la mujer sin acudir al erotismo.

En otras palabras, en los animales no hay erotismo, en el ser humano sí; empero, al propio tiempo, el erotismo puede impedir el cariño y el amor si no suscita la apertura al otro, al tú, al distinto y complementario.

... cuando dos seres se abrazan, no saben lo que hacen; no saben lo que quieren; no saben lo que buscan; no saben lo que encuentran. ¿Qué significa ese deseo que los impulsa al uno hacia el otro? ¿Es el deseo de placer? Sí, desde luego. Pero ésta es una respuesta pobre; porque al mismo tiempo vislumbramos que el propio placer no tiene sentido en sí mismo, que es figurativo. ¿Pero de qué? Tenemos la conciencia viva y 
oscura de que el sexo participa de una red de fuerzas cuyas armonías cósmicas se olvidan, pero no por eso quedan suprimidas; que la vida es mucho más que la vida; quiero decir que la vida es ciertamente mucho más que la lucha contra la muerte, que un retraso del plazo fatal; que la vida es única, universal, toda en todos y que es de ese misterio del que el gozo sexual tiene que participar; (...) (Ricoeur, 1990: 183).

Pero no es este un trabajo sobre Ricoeur; simplemente se menciona para contrastar y entresacar la reflexión de Foucault y mirar su actualidad.

La temática, por tanto, como se intuye, cobra importancia para las humanidades en general pero también, en particular, para cualquier filosofía o epistemología de la educación que busque comprender lo humano en su cabalidad. Y por tal no nos referimos a la totalidad del conocimiento sobre el ser humano, que siempre será un misterio por develar, sino de estar ciertos que tocamos la raíz de su ser y quehacer, esto es, a lo que busca la educación en su sentido clásico y genuino: hacer salir lo que está ahí in nuce, ayudando y colaborando con su realización y vocación fundamental: ser sí mismo.

Por ello mismo, este artículo quiere aportar, desde la perspectiva de Michel Foucault, algunos elementos para la elaboración y/o confección de una reflexión sobre la educación de nuestro tiempo a partir de una cosmovisión, la nuestra, cuyos ejes giran en torno del lenguaje, la locura y la sexualidad, y que tienen incidencia en los demás ámbitos de la actividad humana, la política, el arte, la literatura, el ocio, el trabajo y, sobre todo, como lugar especial, la universidad. Véase, pues, la relevancia de estos temas y la del autor que estamos considerando que, por propios y extraños, es visto como uno de los pensadores más influyentes de los últimos años.

Nuestro tiempo, desde sus raíces en los siglos XVIII y XIX, ha hecho una $<<$ elección original $>>$ que tiene como ejes o focos la locura y la sexualidad (desde luego, el lenguaje pero ello implica un tema aparte que no se abordará en esta exposición). Es decir, así como la Antigüedad tuvo su $<<$ elección original $>>$ en el conocimiento como eje orientador de la cultura (y esto implica la política, la ciencia y la literatura), y la Edad Media en la filosofía de Platón y de Aristóteles, o incluso la filosofía moderna de Descartes a Hegel en la razón, nuestro tiempo la ha tenido en esos ejes mencionados, la locura, la sexualidad y el lenguaje.

El sentido de esa $<<$ elección original $>>$, su significado y alcance, tiene que ver con la inspiración o eje vertebrador de la cultura que vive en torno de 
esos "principios" inspiradores. En palabras de Foucault, quien acuña el término, es "una elección que delimitaría todo un conjunto constituido por el saber humano, las actividades humanas, la percepción y la sensibilidad." (Foucault, 2010: 328).

Se trataría, para ocupar el término alemán, de una weltanschauung, una cosmovisión, o visión del mundo; mejor aún, dado que apunta más a una decisión que a una intelección, se trata de aquello que anima e inspira el conocimiento, los diversos ámbitos de la actividad humana y, en general, la percepción y sensibilidad de la época. Esa época que es la nuestra, nuestro tiempo, nuestra cultura, nuestra civilización que se encuentra, si no animada e inspirada, sí delimitada e impulsada por el tema de la locura y de la sexualidad; ya veremos de qué forma, y eso es justamente el motivo de este trabajo.

En primer lugar, se mostrará la $<<$ dislocación $>>$ de la razón moderna para que, ya no en el centro sino en la periferia, el loco, o la locura, se vuelve el espacio de la verdad o, mejor dicho, sin saberlo y acaso sin quererlo, el loco se torna el sujeto que dice las cosas verdaderas.

Más relevante en este punto de la locura es la elección original (que dejo de poner entre comillas una vez explicado su sentido) en cuanto a lo que señala Foucault: hacia mitad del siglo XVII, el loco era admitido socialmente, si bien mantenido al margen; pero hubo un momento a lo largo de ese siglo en que la sociedad decidió no sólo marginarlo sin encerrarlo y declararlo mentalmente incapaz, o jurídicamente ausente, o como solemos decir coloquialmente, borrarlo del mapa. El manicomio y en un sentido similar la prisión, se volvieron lugares para excluir completamente esas voces discordantes, marginales, de la periferia que, no obstante, mostraban sus propios rasgos y, en algunos casos, rayaban en la genialidad, como fueron los casos de Hölderling, Van Gogh, Artaud, Strindberg.

En palabras del propio Foucault: "quise analizar la elección original que el mundo occidental llevó a cabo mediante estas disposiciones, más bien groseras y poco relevantes, que consistían en encerrar a los locos." (Foucault, 2010: 331).

En segundo lugar, se expondrá el asunto de la sexualidad en el sentido de que, en este rubro, se llevó a cabo otra elección original. Es decir, no tanto que no haya habido pensamiento y filosofía en los siglos XVIII y XIX, sino 
que en el ámbito de la cultura, como se ha dicho, de la percepción y la sensibilidad tuvo mayor envergadura por ejemplo el marqués de Sade que los demás filósofos en su conjunto. Tal sensibilidad y percepción fue confirmada luego por Freud y el psicoanálisis en el sentido de la importancia que revestía la sexualidad para la sociedad y la civilización en general.

Consumada la mayor humillación de colocar al ser humano en un espacio "peor al de los animales" (calificación que el propio Freud realizó), estaba preparado el terreno para que el tema del lenguaje se abriera como horizonte de gran relieve, como el de la mayor elección fundamental de una sociedad que ha probado de todo $\mathrm{y}$ que no le queda sino la construcción $\mathrm{y}$ deconstrucción de sus diversos mundos posibles. Este tema del lenguaje no se abordará porque considero que tiene un tratamiento completamente aparte.

Finalmente, no quedarán sino algunas conclusiones ya enunciadas desde el título y la presentación: que la sociedad de la que somos parte, el tiempo que nos ha tocado vivir, ha hecho elecciones fundamentales que giran en torno de este binomio (locura y sexualidad) que nutre nuestra vida cotidiana, nuestra reflexión y nuestro modo de ser.

\section{La locura y su irrupción en la vida moderna}

Como Sade, Hölderling y otros tienen una influencia determinante en la literatura contemporánea; al grado que Foucault declara al primero el fundador de la literatura moderna. El dato que destaca es cómo en los espacios marginales, la prisión y el manicomio, se hace posible la voz que destaca, que salta, que reluce y que alcanza esos rasgos de genialidad. En otras palabras, cómo el discurso de la periferia, el discurso no relevante, no central, desenfocado si se quiere, llega a tener una relevancia al grado de inspirar una época que, como la nuestra, parece estar animada por él.

Esto es justamente lo que me atrae de Hölderling, Sade, Mallarmé o también de Raymond Roussel y Artaud: el mundo festivo de la locura ha irrumpido repentinamente en la literatura. De este modo mi interés por la literatura se une con mi interés por la locura. (Foucault, 2010: 331-332).

Señala el erudito francés que tanto en la literatura medieval como en la clásica, al menos hasta mediados del siglo XVII, la figura del loco, o antes, la del bufón, era la de revelar la verdad, decirla, señalar lo que iba a pasar, 
aunque no fuera consciente de que la llevaba. Los demás personajes que, a diferencia del loco, poseían libertad, no conocían lo que iba a pasar, o lo que les iba a pasar; el loco, que no tenía dominio de su voluntad o que carecían de ella, sabían lo que iba a pasar, conocían la verdad. Y se daba esa rara paradoja: el libre, el hombre normal, era dueño de su voluntad pero carecía de la verdad (en el sentido de no saber lo que iba a ocurrir); el loco, en cambio, sin saberlo y sin ser dueño de su voluntad, era portador de la verdad en cuanto que la pronunciaba, la emitía, como si la verdad lo usara. Se daba, por tanto, ese binomio locura/verdad. Y es lo que destaca Foucault:

Se puede intentar entonces una historia panorámica de la cultura occidental: esta copertenencia de la verdad y de la locura, esta intimidad entre la locura y la verdad que era posible reconocer hasta principios del siglo XVII, fueron, a continuación, durante un siglo y medio o dos siglos, negadas, ignoradas, rechazadas y escondidas. Ahora bien, a partir del siglo XIX, de un lado, por la literatura y, del otro, más tarde, por el psicoanálisis, se hizo evidente que aquello de lo que se trataba en la locura era de una especie de verdad y que algo que no puede ser más que la verdad aparece sin duda a través de los gestos y los comportamientos de un loco. (Foucault, 2010: 334).

Hoy sabemos con toda claridad que los gestos y comportamientos, incluso en nosotros mismos, que escapan a nuestro conocimiento y voluntad, es decir, nuestras verdades profundas, escapan de nosotros, como escapa de su voluntad lo que los locos saben. Como ellos, nosotros tampoco dominamos ni tenemos a voluntad lo que se esconde de verdadero en nuestro ser, como nos lo ha mostrado el psicoanálisis. Y la precisión ha sido tal que, ahora, basta con que un perito o experto estudie los gestos de nuestro rostro para saber si mentimos o no, si estamos tranquilos o tensos, si hemos hecho esto o lo otro; esto es, como a los locos, se nos muestra que no controlamos ni tenemos a disposición de nuestra voluntad la verdad que se esconde en lo más profundo de nosotros mismos.

Pero no adelantemos conjeturas, vayamos al texto mismo de Foucault, escribe:

Desde la creación del Hospital General, (...) desde las primeras casas correccionales, y hasta el fin del siglo XVIII, la época clásica practica el encierro. Encierra a los depravados, a los padres disipadores, a los hijos pródigos, a los blasfemos, a los hombres que 'tratan de deshacerse', a 
los libertinos. Y, a través de tantos acercamientos y de esas extrañas complicidades, diseña el perfil de su propia experiencia de la sinrazón. (Foucault, 2009a: 174).

Y apunta más adelante:

Encerrar a alguien diciendo de él que es 'furioso', sin tener que precisar si es enfermo o criminal: he allí uno de los poderes que la razón clásica se ha dado a sí misma, en la experiencia que ha tenido de la sinrazón. (Foucault, 2009a: 176).

Pero como se ha señalado, esa marginación, ese aislamiento, esa exclusión no podía ocultarse largo tiempo y, como la erupción de un volcán, tenía que salir, y lo hace en el lenguaje de la poesía impulsada por el Romanticismo del XIX:

Para el pensamiento y la poesía de principios del siglo XIX, lo que la locura dice de sí misma es también lo que dice el sueño en el desorden de sus imágenes: una verdad del hombre, muy arcaica y muy próxima, muy silenciosa y muy amenazante: una verdad debajo de toda verdad, la más cercana del nacimiento de la subjetividad y la más extendida al ras de las cosas; una verdad que es el profundo retiro de la individualidad del hombre y la forma incoativa del cosmos: (...) Así, en el discurso común al delirio y al sueño, se encuentran unidas la posibilidad de un lirismo del deseo y la posibilidad de una poesía del mundo; puesto que locura y sueño son a la vez el momento de la extrema subjetividad y el de la objetividad irónica, no hay contradicción: la poesía del corazón, en la soledad final, exasperada, de su lirismo, resulta ser, por un giro inmediato, el canto originario de las cosas; y el mundo, durante largo tiempo silencioso frente al tumulto del corazón, encuentra allí su voz: "Interrogo a las estrellas, y ellas callan; interrogo el día y la noche, pero no responden. Del fondo de mi mismo, cuando y me interrogo, vienen... sueños no explicados.” (Foucault, 2008: 271-272).

Y de ese modo es como irrumpe la locura no sólo en la poesía y la literatura, sino en la vida misma de los hombres y mujeres que vivimos los albores de este siglo: nuestros sueños son nuestros deseos escondidos por nuestras formas racionales y nuestras convenciones sociales, pero están ahí, inspirando, animando, esperando salir, y alimentando y nutriendo acaso nuestro verdadero yo. 


\section{La explosión de la sexualidad}

De todas las revoluciones antropológicas contemporáneas, la de la sexualidad ha sido, por mucho, la más honda. Si resumimos apretadamente en una síntesis, de las tres revoluciones antropológicas enunciadas por Freud, la copernicana, que tiró al hombre del centro del universo, la de Darwin, que lo colocaba como una especie animal más de la evolución, y la de él mismo como descubridor del inconsciente impulsado por Eros y Tánatos, la que representa una de esas elecciones originales, acaso la de mayor envergadura, es justamente la de la sexualidad.

Entre sus emblemas, nuestra sociedad lleva el del sexo que habla. Del sexo sorprendido e interrogado que, a la vez constreñido y locuaz, responde inagotablemente. Cierto mecanismo, lo bastante maravilloso como para tornarse él mismo invisible, lo capturó un día. Y en el juego donde el placer se mezcla con lo involuntario y el consentimiento con la inquisición, le hace decir la verdad de sí y de los demás. (...) Como si fuese esencial que de ese pequeño fragmento de nosotros mismos pudiéramos extraer no sólo placer sino saber y todo un sutil juego que salta del uno al otro: saber sobre el placer, placer en saber sobre el placer, placer-saber; y como si ese peregrino animal que alojamos tuviese por su parte orejas lo bastante curiosas, ojos lo bastante atentos y una lengua y un espíritu lo bastante bien construidos como para saber muchísimo sobre ello y ser completamente capaz de decirlo, con sólo que uno se lo solicite con un poco de maña. (Foucault, 2009b: 95).

El sexo ya no sólo nos impulsa, sino nos impulsa a saber, se vuelve, por tanto, voluntad de saber; no en balde nos afanamos en conocer, en buscar los elementos básicos y detallados, incluso recónditos, de una sexualidad lo bastante para obtener placer y, al propio tiempo, para conocer cómo se obtiene, cómo se conserva, cómo se incrementa.

Pero al propio tiempo que existe un discurso sobre-exaltado de la sexualidad, un sobre conocimiento de la teoría y de las prácticas sexuales, prevalece un desconocimiento de la sexualidad del individuo, de sí mismo y de sus deseos. Y tal ha sido el mérito del psicoanálisis: poner al descubierto esa fuerza desconocida y somatizada.

En Estética, ética y hermenéutica, expone Foucault: 
Podríamos decir que, a finales del siglo XIX, se produce en las sociedades occidentales un doble fenómeno muy importante: por una parte, un fenómeno general, pero sólo localizable en los individuos, que consiste en el desconocimiento por parte del sujeto de su propio deseo lo que se manifiesta especialmente en la histeria y al mismo tiempo, al contrario, un fenómeno de $<<$ sobresaber $>>$ cultural, social, científico y teórico sobre la sexualidad. Esos dos fenómenos, de desconocimiento de la sexualidad por parte del propio sujeto, y de un $<<$ sobresaber $>>$ sobre la sexualidad por parte de la sociedad, no son contradictorios. Coexisten de forma real en Occidente y uno de los problemas consiste en explicar cómo, en una sociedad como la nuestra, existen a la vez tal producción teórica, tal producción especulativa, tal producción analítica sobre la sexualidad y, al mismo tiempo, un desconocimiento de la propia sexualidad por parte del sujeto. (Foucault, 2010: 801).

De esa suerte, y en medio de esa paradoja, nuestro tiempo ha estado marcado por esa elección original en torno de la sexualidad; el discurso sobre la sexualidad avanza, pero el sujeto retrocede y se vuelve un enigma para sí mismo y para su sexo; como si éste, de repente, cobrara vida, una suerte de voluntad irracional, y lo condujera a capricho, lo condicionara y lo proyectara por caminos insospechados.

Esa paradoja, explica Foucault, de mucho saber sobre la sexualidad y mucho desconocimiento del propio deseo, típico del pensamiento occidental, comparada con otros pensamientos de Oriente, contrapone el supuesto conocimiento científico con la forma más llana, o al menos una cierta forma, de arte. Diríamos que, en suma, mientras que Occidente siempre se preocupó de hacer ciencia sobre la sexualidad, Oriente, aunque también la antigua Grecia y Roma misma, se ocuparon más bien en desarrollar un arte de la sexualidad cuyo propósito no era otro sino el de despertar, mantener e incrementar el placer de la sexualidad.

En Occidente no tenemos un arte erótico. Dicho de otra forma, no se aprende a hacer el amor, ni a darse placer, ni a producir placer en los demás; no aprendemos a maximizar, a intensificar más nuestro propio placer a través del placer de los otros. Esto no se aprende en Occidente y no poseemos otro discurso, ni otra iniciación a este arte erótico, que no sea clandestina y puramente interindividual. Por el contrario, tenemos o intentamos tener, una ciencia sexual -scientia sexualis- sobre 
la sexualidad de la gente, pero no sobre su placer, que no aborda qué es lo que hay que hacer para que el placer sea lo más intenso posible, sino que se pregunta cuál es la verdad de lo que es en el individuo, su sexo o su sexualidad: verdad del sexo y no intensidad del placer. (Foucault, 2010: 803).

En otras palabras, y resumiendo, vivimos una sociedad hipererotizada pero que desconoce, en el ejercicio de su sexualidad, la dinámica de sus deseos y del uso de sus placeres; ciencia pero no arte, y eso vuelve la práctica de la sexualidad un auténtico caos o una suerte de incapacidad de hacer uso de ella, aunque se tenga todo el conocimiento y su saber.

\section{A modo de horizonte, más que de conclusión}

De lo anterior, de esa suerte de paradoja de nuestro tiempo, por un lado, una sociedad hipererotizada y, por otro lado, una represión o prohibición en torno de la sexualidad, brota una línea que, para Foucault, significa el mecanismo o los mecanismos de poder ejercido en la sociedad.

En efecto, pregunta nuestro autor, ¿cómo ha sido posible en Occidente que en un momento dado, digamos tanto en el momento de mayor auge del cristianismo, como en el siglo XIX con la moral burguesa y la forma de estilo victoriana, se haya excluido el tema de la sexualidad (o el tema de la locura, en donde el loco pierde su lugar de la familia, de las relaciones jurídicas y hasta como individuo) y, luego, de repente, haya brotado con mayor ímpetu e impulso al grado de llenar todos los espacios del discurso y del quehacer humanos?

Para nuestro autor se trata de mecanismos de poder; tanto la prohibición cristiana como la de la moral burguesa, y sobre todo de ésta última, lo que logró fue una suerte de hiperproducción de habilidades y capacidades de los individuos.

Nos encontramos con una producción de individuos, una producción de las capacidades de los individuos, de su productividad; todo esto se ha conseguido a través de mecanismos de poder en los cuales existían las prohibiciones, pero existían simplemente como instrumentos. Lo esencial de toda disciplinarización de los individuos no era negativo.

(...) A partir de ahí, me dije: pero, en el fondo, en nuestras sociedades actuales, la forma de poder, ¿es esencialmente prohibir y decir $<<$ no $>>$ ? 
¿No están los mecanismos de poder tan fuertemente inscritos en nuestra sociedad que son ellos los que llegan a producir algo, a multiplicarlo, a intensificarlo? (Foucault, 2010: 813).

En otros términos, prohibir o limitar, disciplinar, es generar productividad; es darle habilidades, capacitar para producir; así el ejército, los obreros $\mathrm{y}$, en general, los medios y modos de producción: la prohibición genera productividad.

Ahora bien, lo que ocurre con el tema de la sexualidad, la prohibición de no hacer esto o aquello, o lo de más allá, no es sino la manera de volverse productivos en un cierto sentido, en cuanto al mecanismo de poder que se genera cuando se tiene el control mediante dicha prohibición.

(...) cuando afirmo que, en el fondo, la sexualidad, aparentemente, es la cosa más prohibida que podemos imaginar, nos pasamos la vida prohibiendo a los niños masturbarse, a los adolescentes que hagan el amor antes del matrimonio, a los adultos hacerlo de tal o cual forma, con tal o cual persona. El mundo de la sexualidad es un mundo plagado de prohibiciones. (Foucault, 2010: 814).

Hay que preguntarse, empero, si no tales prohibiciones, a la manera de como se disciplinan los obreros y los soldados para ser más efectivos y eficientes, no generan precisamente la hiperproducción de sexualidad; o mejor dicho, del discurso de poder que significa la sexualidad.

Entonces, si se había borrado simplemente la sexualidad, si se había prohibido, condenado al olvido, repudiado, negado, ¿cómo es posible que aparezca tal proliferación de discursos, que haya tal obsesión por la sexualidad? La hipótesis de la que proceden mis análisis -que quizá no llevaré a su término, porque no es tal vez la adecuada- sería que, en el fondo, Occidente no niega realmente la sexualidad -no la excluye-, sino que introduce, organiza a partir de ella todo un complejo dispositivo en el que se juega la constitución de la individualidad, de la subjetividad, a fin de cuentas, la manera en la que nos comportamos, en que tomamos conciencia de nosotros mismos. Dicho de otra forma, en Occidente, los hombres, la gente, se individualiza gracias a determinado número de procedimientos y creo que la sexualidad, más que algo específico del individuo, que ha sido arrojado fuera de sí, es constitutiva de ese lazo 
que obliga a la gente a anudarse con su identidad bajo la forma de la subjetividad. (Foucault, 2010: 814).

$\mathrm{Y}$ tenemos, entonces, ese mecanismo de control y de poder, en otros tiempos con la predominación del cristianismo, luego con la moral victoriana, y en nuestro tiempo con el discurso del saber científico de la sexualidad.

A final de cuentas, como escribe nuestro autor, no hay que preguntar cómo y hacia dónde va el poder, que siempre se ejerce en todos lados y todo el tiempo, en la casa, la escuela, el trabajo y en toda relación humana, sino cuáles son sus mecanismos. Y la sexualidad representa uno de esos campos y, como se ha indicado, una de las elecciones originales de nuestro tiempo, junto con la influencia de la locura en el lenguaje de la literatura y de la poesía.

Esa es nuestra sociedad, esos somos nosotros. Incluso la tarea de ocuparse de sí mismo se encuentra ligada al ejercicio del poder; desde luego, Foucault no entiende el poder en el sentido político, solamente, como se ha vislumbrado, aunque ese ocuparse de sí mismo se infiera de la voluntad del sujeto de ejercer el poder político sobre los demás, puesto que "la necesidad de preocuparse por sí mismo está ligada al ejercicio del poder" (Foucault, 2006: $51)$.

De nueva cuenta, no se trata de saber de dónde viene y a dónde va el poder, ni siquiera de definirlo o establecerlo como saber, sino de darse cuenta cómo corre, cómo ocurre en los diversos ámbitos de la actividad humana, acaso para caminar con él, para experimentar la sensibilidad y la percepción de esta sociedad, de esta cultura que vivimos, hipererotizada y prohibitiva con la sexualidad. Tales son los aportes de los estudios y de las reflexiones de un pensador como Foucault.

Así pues, las elecciones originales, o la elección original en torno de la locura y la sexualidad (además del lenguaje que sólo se ha enunciado), como formas disciplinarias mediante la exclusión o la represión, como prohibiciones, no han producido literalmente otra cosa que la explosión de la poesía y del erotismo, justamente como horizontes de productividad y de influencia de la mayor envergadura en nuestro tiempo, tanto en la literatura como en los diversos ámbitos, insisto, del quehacer humano. 
Ahora bien, y acaso sea esto lo que aporta Foucault, la literatura que recoge y adopta esas elecciones originales de la locura y la sexualidad se muestra como un elemento transgresor frente al poder, y el lenguaje encarna esa posibilidad, posibilidad de existencialización, de realización del sujeto, no como esencia preestablecida, sino de permanente ensayo de sí mismo.

Para el tema educativo, la locura y la sexualidad como temas abordados desde el tamiz foucaultiano, la conclusión podría ser ésta: mostrar al sujeto humano, en primer lugar, que el discurso central no es el más importante (lo que opinan los demás, o lo que opina quien detenta el poder, o quien tiene la opinión dominante), sino que existen discursos periféricos que pueden ser también muy valiosos y que, de hecho, nos muestran que es nuestro mejor asidero para comenzar a ser humanos (lo propio, lo familiar, lo nuestro, lo que compartimos con nuestra pequeña comunidad, sea en el hogar o en el trabajo). En pocas palabras, que el discurso periférico, como el de los locos excluidos, puede seguir mostrando verdades aunque el discurso del poder (el del centro y del dominio) muestre otras cosas. Metafóricamente, no es necesario ir a la capital para conocer el mundo; también el mundo está formado por la provincia.

El discurso sobre la sexualidad puede verse con la misma incidencia para el ámbito educativo, y esto es lo que se puede considerar en segundo lugar; que la sexualidad, tanto como conocimiento cuanto como práctica, supone una suerte de exploración e incursión sobre sí mismo; una suerte de dignificación del propio cuerpo y una mirada más aguda sobre su dignidad. Lo cual podría darse en la medida de denunciar su abuso por parte de la tendencia predominante que busca productividad y comercialización. En fin, sólo son atisbos que pueden incidir en la revisión de nuestras reflexiones sobre el ámbito educativo.

\section{Fuentes de CONSUlta}

- BAUMER, Franklin L. (1985): El pensamiento europeo moderno. Continuidad y cambio en las ideas, 1600-1950, México: Fondo de Cultura Económica.

- DARWIN, Charles (1981): El origen de las especies, México: Diana. 
- FOUCAULT, Michel (2006): La hermenéutica del sujeto. Curso en el Collège de France (1981 - 1982), México: Fondo de Cultura Económica.

(2008): Historia de la locura en la época clásica II, México: Fondo de Cultura Económica.

(2009a): Historia de la locura en la época clásica I, México: Fondo de Cultura Económica.

(2009b): Historia de la sexualidad 1. La voluntad de saber, México: Siglo XXI.

(2010): Obras esenciales. I. Entre filosofía y literatura, II. Estrategias de poder, III. Estética, ética y hermenéutica, Madrid: Paidós.

- FREUD, Sigmund (2008): Obras completas V. La interpretación de los sueños (segunda parte). Sobre el sueño (1900-1901), Buenos Aires: Amorrortu.

- $\quad$ RICOEUR, Paul (1990): Historia y verdad, Madrid: Encuentro. 